\title{
Advance of Etiologies and Treatments on Schizophrenia
}

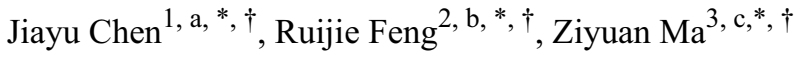 \\ ${ }^{1}$ Future Leadership Academy; Lingshui Li Autonomous County, Hainan; 572400, China \\ ${ }^{2}$ Cushing Academy; Ashburnham, Boston; MA; 01430, US \\ ${ }^{3}$ University of California, Irvine; School of Biological Science; Irvine; CA; 92617, US \\ ${ }^{\dagger}$ These authors contributed equally to this work.
}

\begin{abstract}
Schizophrenia is a severe psychiatric disorder. Among the globe, almost $70 \%$ of people with schizophrenia would experience hallucinations that make them feel insecure and progressively weakened. Etiologies and treatments of this perilous disease, therefore, are supposed to be studied in depth. Although the exact causes are still unknown, scientists highly suggest that this disorder results from the combination of genes and environments. For genetic influences, genes such as NR3C2, Dysbindin-1 (DTNBP1), Neuritin-1 (NRN1), KPNB3, and KPNA3 play insignificant roles in the development of schizophrenia. For environmental influences, researchers collected data from different aspects to infer the causes of schizophrenia. The reasons, including season of birth, urbanization, are not related to schizophrenia causation. Furthermore, if pharmacological interventions such as chlorpromazine, followed by some psychotherapy at an early stage, schizophrenia has a chance of being cured and not relapsing. Many drugs on the market target G-protein-coupled receptors. To improve their bioavailability, a new technique called lipid-based selfnanoemulsifying drug delivery systems formulations assists with the absorption of them.
\end{abstract}

\section{Introduction}

Schizophrenia is a mental disorder characterized by abnormal behaviors and declined cognitive ability. People with schizophrenia seem to be out of touch with reality and society, causing severe distress for their family members and themselves. Increasing research and clinical evidence claim that schizophrenia is caused by a series of neurodevelopmental problems such as dysfunction in dopaminergic, glutamatergic, serotonergic, and gammaaminobutyric acid (GABA) signaling. Because it is a multifactorial and chronic disease, the etiology of schizophrenia is not well understood. But there is consensus that both genetic and environmental factors play significant roles in this disorder. Since genes can control the genotype and phenotype of humans, abnormal activity and quantity in genes can cause a change in brain activity. For instance, the gene-NR3C2 receptor, which regulates the HPA, is correlated with schizophrenia. Moreover, when the regulators that transmit homeostasis change, they also increase the chance of disease. In addition to the influence of genes, the role of the environment cannot be ignored. Drug taking, the pressure from society, seasonal variation all affect the incidence of schizophrenia. Without specific therapies, the negative symptoms can exist for a long period. And this condition can potentially lead patients to uncontrollable and perishing situations such as attempting suicide. But some patients can be cured after medication and psychotherapy. In this review, to better study schizophrenia, we intend to discover the genetic and environmental influences on schizophrenia and its treatments involving both medication and psychological intervention.

\section{Overview of schizophrenia}

Schizophrenia is a severe and chronic disorder. Its symptoms contain hallucination, delusion, disorganized speech, disturbances of emotions, etc. [1]. This disorder, however, can affect educational and occupational performance. One study estimates that $0.3-0.7 \%$ of people are affected by schizophrenia within the world's population. Within the affected population, $4.9 \%$ of schizophrenics often commit suicide during their lifetimes and near the illness onset. Thus, schizophrenics are $2 \sim 3$ times more likely to die early than normal people since schizophrenia co-occurs with various other disorders. The incidence is higher in males than females (Table 1). Schizophrenia is a multifactorial disorder. According to this, this essay will explain multiple factors that cause schizophrenia and treatment. 
Table 1. Studies reporting higher incidence rates in male compared to female subjects with schizophrenia. [2]

\begin{tabular}{|c|c|c|c|c|c|}
\hline $\begin{array}{c}\text { Author country } \\
\text { time }\end{array}$ & $\begin{array}{c}\text { Population } \\
\text { (N) }\end{array}$ & $\begin{array}{c}\text { Diagnostic } \\
\text { criteria } \\
\text { males(rate/100,000/ } \\
\text { year) }\end{array}$ & $\begin{array}{c}\text { Incidence rates on } \\
\text { females(rate/100,000/ } \\
\text { year) }\end{array}$ & $\begin{array}{c}\text { Incidence rates on } \\
\text { female sex } \\
\text { ratio }\end{array}$ \\
\hline $\begin{array}{c}\text { Munk-Jorgensen } \\
\text { (1986) Denmark, }\end{array}$ & 10.8 & ICD-8(cl,re) & 19.3 & 10.8 & 1.79 \\
\hline $\begin{array}{c}\text { Cooper et al. } \\
\text { (1987) UK, 1978- } \\
80\end{array}$ & 202,214 & ICD-9(cl,br) & 28 & 14 & 2 \\
\hline
\end{tabular}

(WHO), more than 350 million individuals suffer from the disease. It affects many people, from the elderly to teenagers, no matter what their careers are. The performance of depressive patients is diverse, but all share a black mood. They easily lose interest in everything as well as get anorexia1. Disturbances of circadian rhythms are also a cardinal feature, which involves in insomnia. A mild depression episode manifests as sadness, anhedonia, and a feeling of worthlessness, whereas Major depressive disorder (MDD) is classified by a recurring intention to commit suicide. Suicidal tendency is exceedingly common among people with MDD, almost half of which. This tendency derives from a low sense of self-worth [3], making them disapprove of themselves and occasionally feel guilt. In general, depression is a dangerous psychological sickness and heavily detrimental to people's mental and physical health.

\section{Genetic factors}

Due to inheritance, generations are connected by genes. Single mutation on the nucleotide sequence or change in protein can potentially risk people from developing specific disorders such as schizophrenia.

\subsection{NR3C2 gene}

Within schizophrenia patients, there is the abnormal activity of the hypothalamic-pituitary-adrenal (HPA) axis. The activity of HPA, however, is related to the DNA methylation of genes. The mineralocorticoid receptor gene, NR3C2, can regulate the HPA activity [4]. Several researches have indicated that the methylation level of NR3C2 can affect the development of schizophrenia through its different sites but alcoholism in schizophrenia as well [5].

\subsubsection{NR3C2 methylation in the P1 promoter}

Through the $50 \mathrm{CpG}$ sites studied in the $\mathrm{P} 1$ region, a decrease in the methylation level of NR3C2-2-2 CpG sites in the $\mathrm{P} 1$ promoter is observed in the experimental group (fig.1a). When comparing the DNA methylation level of the $\mathrm{P} 1$ promoter in males and females (fig $1 \mathrm{~b} \& 1 \mathrm{c}$ ), a significant difference $(\mathrm{p}<0.05)$ on the methylation of NR3C2-2-2 CpG site is observed between the males in experimental and control groups (fig 1b). Moreover, there is an increased methylation level of NR3C2-1$12(p=0.0144)$ and NR3C2-2-7(0.0427) $\mathrm{CpG}$ sites in the female experimental groups (fig 1c). Thus, schizophrenia is sex-dependent with a higher methylation level of NR3C2-1-12 and NR3C2-2-7 in females. Moreover, methylation in different $\mathrm{CpG}$ sites of NR3C2 can increase the risk of schizophrenia.

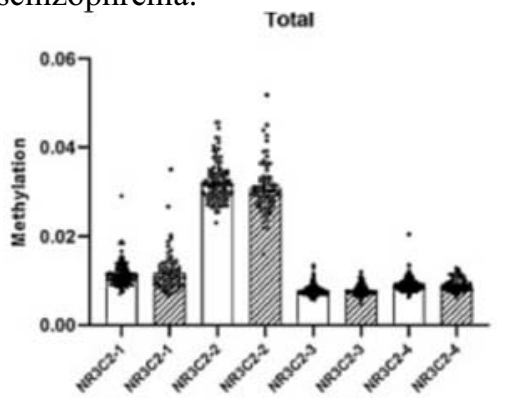

Fig 1a

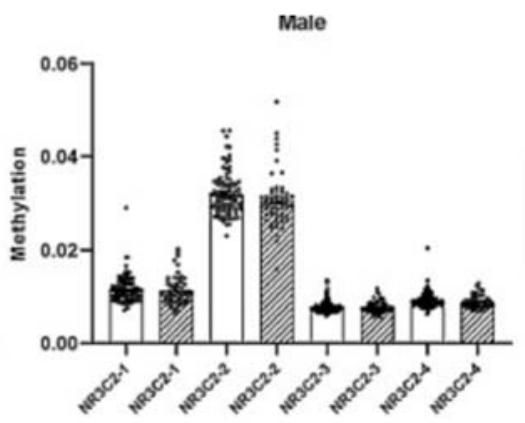

Fig $1 \mathrm{~b}$ 


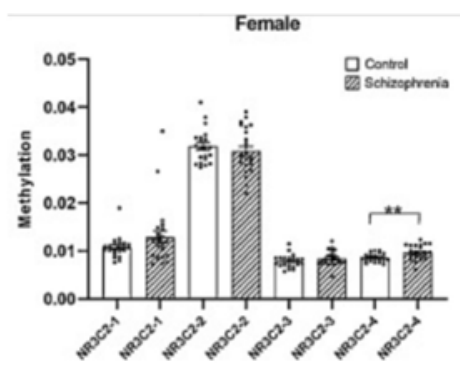

Fig 1c

Figure 1. DNA methylation levels of the 5' region of the $\mathrm{NR} 3 \mathrm{C} 2$ gene in schizophrenia patients and matched healthy controls. [3]

\subsubsection{NR3C2 methylation in NR3C2-4 region}

Although there is no significant difference in methylation level of NR3C2-4 region shown in the figure (fig. 1a,1b,1c), individual $\mathrm{CpG}$ sites-NR3C2-4-20-reveal a correlation $(p=0.0367)$ between schizophrenia and the NR3C2-4 region (Table 2), for males of the experimental group, methylation levels of NR3C2-4-8( $\mathrm{p}=0.0210)$, NR3C2-4-17 $(p=0.0129)$, and NR3C2-4-21 $(p=0.0422)$ decreased significantly compared to the control group. For females in the experimental group, however, methylation levels of NR3C2-4-4( $p=0.0204)$, NR3C2-4$14(\mathrm{p}=0.0122)$, and $\mathrm{NR} 3 \mathrm{C} 2-4-24(\mathrm{p}=0.0327)$ are significantly different from that of the control group. Due to the findings above, schizophrenia is associated with both sex and $\mathrm{CpG}$ sites in NR3C2 promoter (P1) and NR3C2-4 region. Different CpG sites can either decrease or increase the risk of developing schizophrenia.

Table 2. CpG sites with significant differences in methylation between schizophrenia patients and matched healthy controls. [5]

\begin{tabular}{|c|c|c|c|c|c|c|}
\hline Total & \multicolumn{3}{|c|}{ control $\mathrm{N}=128$} & \multicolumn{3}{|c|}{ patients $\mathrm{N}=80$} \\
\hline Target & $\begin{array}{l}\mathrm{CpG} \\
\text { site }\end{array}$ & $\begin{array}{c}\text { mean } \\
\text { methylation }\end{array}$ & $\mathrm{SD}$ & $\begin{array}{c}\text { mean } \\
\text { methylation }\end{array}$ & SD & P-value (Ttest) \\
\hline$N R 3 C 2-2$ & 2 & 0.0192 & 0.0076 & 0.0162 & 0.0085 & 0.0101 \\
\hline$N R 3 C 2-4$ & 20 & 0.0083 & 0.003 & 0.0074 & 0.0028 & 0.0367 \\
\hline Male & \multicolumn{3}{|c|}{ control $\mathrm{N}=106$} & \multicolumn{3}{|c|}{ patients $\mathrm{N}=56$} \\
\hline Target & $\begin{array}{l}\mathrm{CpG} \\
\text { site }\end{array}$ & $\begin{array}{c}\text { mean } \\
\text { methylation }\end{array}$ & SD & $\begin{array}{c}\text { mean } \\
\text { methylation }\end{array}$ & SD & $\begin{array}{l}\text { P-value } \\
\text { (Ttest) }\end{array}$ \\
\hline NR3C2-2 & 2 & 0.0187 & 0.0072 & 0.0153 & 0.0079 & 0.0078 \\
\hline$N R 3 C 2-4$ & 8 & 0.0086 & 0.0029 & 0.0075 & 0.0023 & 0.021 \\
\hline NR3C2-4 & 17 & 0.0079 & 0.003 & 0.0069 & 0.002 & 0.0129 \\
\hline$N R 3 C 2-4$ & 20 & 0.0084 & 0.0032 & 0.0074 & 0.0026 & 0.0357 \\
\hline NR3C2-4 & 21 & 0.0092 & 0.0027 & 0.0083 & 0.0029 & 0.0422 \\
\hline Female & \multicolumn{3}{|c|}{ control $\mathrm{N}=22$} & \multicolumn{3}{|c|}{ patients $\mathrm{N}=24$} \\
\hline Target & $\begin{array}{l}\mathrm{CpG} \\
\text { site }\end{array}$ & $\begin{array}{c}\text { mean } \\
\text { methylation }\end{array}$ & SD & $\begin{array}{c}\text { mean } \\
\text { methylation }\end{array}$ & $\mathrm{SD}$ & $\begin{array}{l}\text { P-value } \\
\text { (Ttest) }\end{array}$ \\
\hline$N R 3 C 2-1$ & 12 & 0.0122 & 0.006 & 0.0192 & 0.0118 & 0.0144 \\
\hline$N R 3 C 2-2$ & 7 & 0.0215 & 0.0071 & 0.0264 & 0.0089 & 0.0427 \\
\hline$N R 3 C 2-4$ & 4 & 0.0093 & 0.0028 & 0.0113 & 0.003 & 0.0204 \\
\hline NR3C2-4 & 14 & 0.0115 & 0.0032 & 0.0171 & 0.0096 & 0.0122 \\
\hline$N R 3 C 2-4$ & 24 & 0.0081 & 0.003 & 0.0105 & 0.0042 & 0.0327 \\
\hline
\end{tabular}




\subsection{Dysbindin-1 (DTNBP1) and Neuritin-1 (NRN1) genes}

Dysbindin-1 gene (DTNBP1) acts as a modulator for pre and post synaptic transmission homeostasis by regulating the release of neurotransmitters. Patients with schizophrenia always show lower levels of DTNBP1 mRNA in the dorsolateral prefrontal cortex and hippocampus. Thus, glutamate output is decreased, and dopamine release is increased. In addition, more research found that regions 6p25-p22 (where DTNBP is located) and NRN1 are involved in schizophrenia and intelligence as well [6]. Neuritin-1 genes (NRN1), on the other hand, is an immediate-early gene that is induced by synaptic activity by activating NMDA receptors.

According to table 3, NRN1 HAP-risk-C-C and DTNBP1 SNP2 A allele can lead to a higher risk of schizophrenia $(p=0.001)$. In other words, individuals who carry the HAP-risk C-C would have a higher risk of developing schizophrenia. Moreover, table 3 also shows that HAP-risk C-C and SNP2 (rs2743864) have a combined effect on the risk of developing schizophrenia by interacting with each other (Table 3). Both factors could work together to further risk the individual for having schizophrenia.

Table 3. DTNBP1 SNP2 (rs2743864) and NRN1 (rs645649rs582262) on the risk for developing schizophrenia-spectrum disorders (logistic regression model). [7]

\begin{tabular}{|l|c|}
\hline \multicolumn{1}{|c|}{ Main effects } & p-value \\
\hline $\begin{array}{l}\text { DTNBP1 rs2743864 (A } \\
\text { carriers vs GG) }\end{array}$ & 0.136 \\
\hline $\begin{array}{l}\text { NRN1 HAP-risk (non- } \\
\text { carriers vs C-C carriers) }\end{array}$ & 0.001 \\
\hline Sex & $<0.001$ \\
\hline Interaction & 0.033 \\
\hline rs2743864*HAP-risk C-C & \\
\hline
\end{tabular}

\subsection{KPNB3 gene and KPNA3 gene}

KPNB3 gene and KPNA3 gene are under the karyopherins family, responsible for transporting macromolecules containing nuclear import/export signals between the nucleus and cytoplasm [8]. Through the research, the single nucleotide polymorphisms (SNPs) on both KPNB3 and KPNA3 locus can contribute to schizophrenia genetically [9]. Within the SNPs, rs626716 at the KPNB3 locus, rs3782929, and rs3736830 at the KPNA3 locus is detected. In table 4, the data on the pvalue indicates that the SNP combination on both KPNB3 and KPNA3 (rs626716-rs3782929 and rs626716- rs3736830) can contribute to the development of schizophrenia.

Different months

Table 4. The conditional test for SNP combinations. [9]

\begin{tabular}{|c|c|}
\hline Combinations & P value \\
\hline rs626716-rs3782929 & $0.001 \mathrm{a}$ \\
\hline CG & 0.028 \\
\hline CA & 0.448 \\
\hline TG & 0.021 \\
\hline TA & 0.514 \\
\hline All & \\
\hline rs626716-rs3736830 & 0.234 \\
\hline CC & $0.003 \mathrm{a}$ \\
\hline CG & 0.852 \\
\hline TC & 0.13 \\
\hline TG & 0.013 \\
\hline All & \\
\hline
\end{tabular}

a. The p-value is significant at $5 \%$ after the Bonferroni correction for multiple tests.

\section{Environmental factors}

Some factors that people ignore can also increase the incidence of developing schizophrenia. For example, taking drugs can lead people to become insane. Other factors, such as living in a new environment, do affect people physically and mentally. When some people move into a new place, they tend to be nervous and feel pressure. After these feelings accumulate to a threshold, people tend to have psychiatric disorders.

\subsection{Substance Misuse}

Drug addiction releases people's pressure and lets them feel a brief pleasure. However, it has adverse effects on people and may lead to psychiatric disorders. The symptoms of schizophrenia, such as hallucinations, delusions, poor concentration, are all similar to the symptoms of substance abuse. When people are addicted to drugs, the substance in drugs alters the brain's chemistry. It causes irrevocable damage that may lead to mental disorders, such as schizophrenia. According to the research published in Milan, Italy, cannabis is 5.2 times more likely to increase the risk of developing schizophrenia, and alcoholism is 3.4 times more likely. Hallucinogens broaden the risks by 1.9 times. 
Table 5. Substance Abuse on Schizophrenics Have Higher Rates Than General Population. [3]

\begin{tabular}{|c|c|c|c|c|}
\hline \multirow[t]{2}{*}{ Abused Substance } & \multicolumn{2}{|c|}{ Schizophrenia Patients } & \multicolumn{2}{|c|}{ General Adult Population } \\
\hline & $\begin{array}{l}\text { Reported Rate of } \\
\text { Use (Range } \\
\text { From Various } \\
\text { Studies) }\end{array}$ & $\begin{array}{c}\text { Reported } D S M-I V \\
\text { Abuse or } \\
\text { Dependence } \\
\text { (Range From } \\
\text { Various Studies) }\end{array}$ & $\begin{array}{c}\text { Rate of Use (Past month for } \\
\text { ages } 18 \text { or older) (NSUDH) } \\
\text { (SAMHSA2008) }\end{array}$ & $\begin{array}{l}D S M-I V \text { Dependence } \\
\text { in Past Year }\end{array}$ \\
\hline Nicotine & $60 \%-90 \% 0^{a}$ & $28.5 \%{ }^{b}$ & $25.9 \%$ & $12.80 \%$ \\
\hline Cannabis & $17 \%-80.3 \%^{c}$ & $50.80 \%$ & $5.8 \%-16.4 \%$ & $1 \%$ \\
\hline Alcohol & $21 \%-86 \%{ }^{d}$ & $43.1 \%-65 \%$ & $2.9 \%-17.9 \%$ e & $5.10 \%$ \\
\hline Cocaine & - & $23 \%$ & $0.7 \%-1.7 \%$ & $0.09 \%{ }^{\mathrm{f}}$ \\
\hline
\end{tabular}

Note: Prevalence ranges arc merely intended to illustrate the consistency of the trend in this population because they represent diverse sampling methods among studies done with different adult populations and measures of abuse. The average rates of use and abuse or dependence in the general adult population were derived from the 2007 National Survey on Drug Use and Health - and secondary analyses of the 2000-2002 National Epidemiologic Survey on Alcohol and Related Conditions - and are not intended to provide control baselines but as expedient markers for general comparison. DSM-IV, Diagnostic and Statistical Manual of Mental Disorders (Fourth Edition); NSUDH, National Survey on Drug Use \& health; SAMHSA, Substance Abuse and Mental Health Services Administration.

${ }^{a}$ Current daily smokers.

${ }^{\mathrm{b}}$ Based on a calculated odds ratio of 2.8 higher than in controls.

'Past month.

${ }^{\mathrm{d}}$ Alcohol misuse, abuse, or disorder.

eHeavy use.

fStimulants.

Table 5 shows the schizophrenia patients report consistently higher rates of substance abuse than the general population, notably with respect to 4 licit (nicotine and alcohol) and illicit (cannabis and cocaine) substances. From these four substances, nicotine and cannabis are the two that are frequently abused. More than $70 \%$ of patients with chronic schizophrenia are nicotine dependent [3]. Weiser et al. investigated a sample of more than 14,000 adolescents followed over a period of 4 to 16 years and found that adolescents who smoked more than 10 cigarettes per day at initial evaluation were significantly more likely to be hospitalized for schizophrenia during the follow-up period. The "selfmedication hypothesis" suggests that smoking helps eliminate the deficits observed in schizophrenia of cognition. Post-mortem studies reported that schizophrenics' brains have deficits in inhibitory neurons. Thus, schizophrenics cannot effectively rehabilitate drugs. Schizophrenia patients abuse cannabis not only for hedonic properties but also for other pharmacological effects, such as release pressure, etc. [9]. The results from a total of 759 study members indicate that cannabis users by age 15 and 18 exhibited more schizophrenic symptoms at age 26 than controls [3].

\subsection{Season of Birth}

Different months and seasons might affect the incidence of schizophrenia. A 5\%-8\% excess birth of children in winter and spring later develop schizophrenia in the northern hemisphere. Within 200 studies, most of them reveal a decrease in late summer births and an increased number of winter-spring births of those individuals with the disease [10].

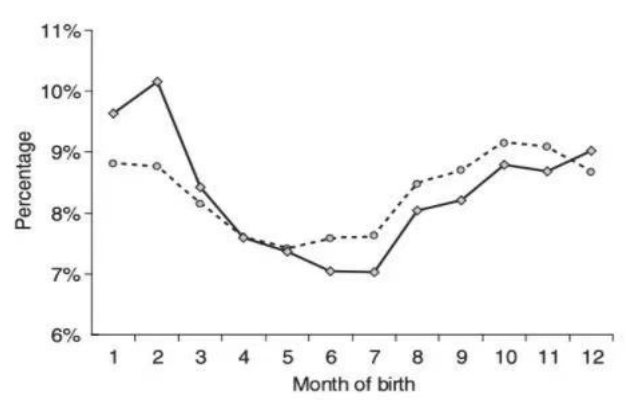

Figure 2. proportion of births vs month(1950-89) for (- - --) the general population and (-) schizophrenia patients [10]

Torreyetal found patients with schizophrenia born from 1925 to 1975 and was admitted to state psychiatric 
hospitals in Ohio, Pennsylvania, Virginia, and North Carolina. The table 6 below represents the percentage of excess or deficit births pooled from inpatients with schizophrenia born during the years 1925 to 1975 for
Ohio $(\mathrm{OH})$, Pennsylvania (PA), Virginia (VA), and North Carolina (NC).

Table 6. Percentage of excess or deficit births of schizophrenics from Ohio (OH), Pennsylvania (PA)

\begin{tabular}{|c|c|c|c|c|c|c|c|c|}
\hline \multicolumn{9}{|c|}{ Virginia (VA), and North Carolina (NC) in 1925 to 1975. [10] } \\
\hline $\begin{array}{l}\text { SCHIZOPHRENIA } \\
\text { CLASSIFICATION }\end{array}$ & STATE & DEC & JAN & MAR & MAY & JUL & SEP & NOV \\
\hline \multirow{5}{*}{ Schizophrenia, NOS } & $\mathrm{OH}$ & 6.5 & 3.9 & 6.6 & -2.3 & -4 & -2.7 & -7.1 \\
\hline & PA & 10.9 & 9.3 & 7.9 & -2.7 & 4.1 & -2.5 & -8.2 \\
\hline & VA & 7.7 & 3.6 & 1.6 & 2.1 & 8.8 & -9.2 & -11.9 \\
\hline & $\mathrm{NC}$ & 8 & 7.2 & -2.8 & -6 & -0.8 & 1 & -10.2 \\
\hline & Total & 8.2 & 5.5 & 3.7 & -0.5 & 4.3 & -5.7 & -10.1 \\
\hline \multirow{5}{*}{$\begin{array}{l}\text { Schizophrenia, } \\
\text { paranoid }\end{array}$} & $\mathrm{OH}$ & 9.5 & 0.9 & 1.7 & -5.5 & 1.2 & -3.2 & 6.5 \\
\hline & PA & -1.9 & 7.4 & -2.4 & 0.1 & 2.8 & 1.9 & -1.8 \\
\hline & VA & 0.4 & 3.6 & 1.3 & -1.3 & 4.2 & 0.6 & -6.2 \\
\hline & $\mathrm{NC}$ & -5.9 & 10.2 & 17.3 & -10 & -3 & -2.1 & 19.5 \\
\hline & Total & 0.9 & 4.1 & 3.7 & -2.9 & 2.3 & 0 & 1.1 \\
\hline \multirow{5}{*}{$\begin{array}{l}\text { Schizoaffective } \\
\text { disorder }\end{array}$} & $\mathrm{OH}$ & -4.9 & 3.1 & 6.6 & -3.7 & 0.9 & -0.9 & 1.2 \\
\hline & PA & 4.2 & 17.3 & -0.3 & -1.4 & 0.8 & 2.9 & -3.8 \\
\hline & VA & -3.1 & -0.5 & 9.1 & 2.3 & -4.5 & -5.6 & 2.2 \\
\hline & $\mathrm{NC}$ & -12.6 & 6.8 & 21.6 & -10.8 & 2.9 & -10.8 & -8 \\
\hline & Total & -3 & 4.8 & 9.3 & -1.1 & -1.9 & -3.9 & -0.1 \\
\hline
\end{tabular}

Though there was documented winter birth excess for those with major psychoses, the actual causal event could have occurred in summer, fall, or at conception in the spring.

Besides, O'Callaghan et al. examined 3253 persons with schizophrenia ascertained by case registers and found a $5 \%$ excess of births from the first quarter. As we can see, the percentage in each study is not high. So the season of birth does account for a small but significant risk for schizophrenia.

The reason why the season of birth causes schizophrenia is that seasonal variation in exposure to these unmeasured environmental risk factors, such as temperature, humidity, and infections, combined with vulnerability only during prenatal or early neonatal life, would translate into the observed excess of schizophrenic births at certain times of the year. Thus, this environmental factor cannot be underestimated.

\subsection{Ethnic minorities and Immigration}

Moving to a new place or encountering different races may affect people's mental health and sometimes will increase the rate of getting schizophrenia. It is still unexplained why there is a high incidence of schizophrenia among ethnic minorities in Western Europe. Some researchers refer to the reason for the adverse social experiences, such as perceptions of discrimination and exclusion. Wim Veling et al. put their focus on ethnic group identity that first and secondgeneration ethnic minorities who developed schizophrenia would identify themselves less often and less positively with their own ethnic group than their siblings and nonpsychotic controls and that they would more often have an assimilated or marginalized identity and less often a separated or integrated identity [11].

Willem Anne Veling computed separately for immigrants living in high and low ethnic density neighborhoods and done for all immigrant groups 
together and for each immigrant group [12]. In table 7, we can see that $75 \%$ of the immigrants are schizophrenics.

Table 7. Percentage of schizophrenia disorder in immigrants is higher than native Dutch in The Hague, 1997-2005. [12]

\begin{tabular}{|c|c|c|c|c|}
\hline \multirow{2}{*}{} & \multicolumn{2}{|c|}{ Native Dutch } & \multicolumn{2}{c|}{ Immigrants } \\
\cline { 2 - 5 } & No. & $\%$ & No. & $\%$ \\
\hline Patients & 226 & 48 & 240 & 52 \\
\hline Gender & 157 & 69 & 173 & 72 \\
\hline Male & 69 & 31 & 67 & 28 \\
\hline Female & 176 & 78 & 203 & 85 \\
\hline Age, years & 50 & 22 & 37 & 15 \\
\hline $15-34$ & 142 & 63 & 179 & 75 \\
\hline \begin{tabular}{c}
$35-54$ \\
\hline $\begin{array}{c}\text { Diagnosis } \\
\text { spectrum } \\
\text { disorderc }\end{array}$
\end{tabular} & \multicolumn{3}{|c|}{} \\
\hline \begin{tabular}{c} 
Schizophrenia \\
\hline
\end{tabular} & 50 & & \\
\hline
\end{tabular}

The incidence among immigrants increased when they lived in neighborhoods where their own ethnic groups are in small portions. Whereas in high ethnic density neighborhoods, the incidence rate was not significantly high.

As a result, ethnic group identity plays a role in the cause of psychiatric disorders. The same ethnic group can bring familiarity and closeness when people migrate to other countries or cities.

\subsection{Urbanization}

Higher levels of urbanicity of place of birth and of the place of residence increase the risk for adult schizophrenia [13]. Preben Mortensen, M.D. found that the more time a person spends before the age of 15 in an urban area, the higher his or her risk of developing schizophrenia. Some experts said that when people live in an urban place, they will have a higher likelihood of social stress and social adversity. Kit Yee Chan et al. suggest that the mechanisms driving the risks of illness in urban areas are likely to be associated with modern urban lifestyles. The lower rates of schizophrenia found when China was less industrialized are consistent with studies that reported lower illness rates in the low and middle income countries [10].

Table 8 shows the 175 municipalities in Denmark classified according to the degree of urbanization and geographical distance from the residence to the nearest major road. The table 8 shows the residents who live near the capital almost always had higher rates of getting schizophrenia than people who live in rural places [14].

Table 8. The Relative Risk of Schizophrenia Patients of Geographical Distance at the 15th birthday where 10,394 developed schizophrenia 1970-2001. [14]

\begin{tabular}{|l|l|l|l|l|l|}
\hline \multirow{2}{*}{$\begin{array}{c}\text { Geographical } \\
\text { distance to } \\
\text { nearest major } \\
\text { road at 15th } \\
\text { birthday }\end{array}$} & \multicolumn{4}{|l|}{ Relative Risk (95 percent Confidence Interval) * } \\
\cline { 2 - 6 } & Place of residence at 15th birthday \\
\cline { 2 - 6 } & Capital & $\begin{array}{l}\text { Capital } \\
\text { suburb }\end{array}$ & $\begin{array}{l}\text { Provincial } \\
\text { city }\end{array}$ & Provincial town & Rural area \\
\hline $0-50 \mathrm{~m}$ & $\begin{array}{l}2.16(1.76, \\
2.65)\end{array}$ & $\begin{array}{l}1.42(1.12, \\
1.80)\end{array}$ & $\begin{array}{l}1.34(1.09, \\
1.65)\end{array}$ & $1.14(0.97,1.35)$ & $\begin{array}{l}\text { 1.10 }(0.95, \\
1.27)\end{array}$ \\
\hline $50-100 \mathrm{~m}$ & $2.15(1.71$, & $1.53(1.25$, & $1.47(1.21$, & $1.26(1.07,1.49)$ & $1.04(0.88$, \\
& $2.70)$ & $1.87)$ & $1.80)$ & & $1.24)$ \\
\hline
\end{tabular}




\begin{tabular}{|c|c|c|c|c|c|}
\hline $100-250 \mathrm{~m}$ & $\begin{array}{l}2.34(2.00, \\
2.73)\end{array}$ & $\begin{array}{l}1.51(1.30 \\
1.75)\end{array}$ & $\begin{array}{l}1.48(1.27 \\
1.72)\end{array}$ & $1.20(1.05,1.37)$ & $\begin{array}{l}1.02(0.89 \\
1.17)\end{array}$ \\
\hline $250-500 \mathrm{~m}$ & $\begin{array}{l}2.25(1.95, \\
2.59)\end{array}$ & $\begin{array}{l}1.47(1.28 \\
1.70)\end{array}$ & $\begin{array}{l}1.31(1.12, \\
1.54)\end{array}$ & $1.22(1.06,1.39)$ & $\begin{array}{l}1.04(0.91 \\
1.20)\end{array}$ \\
\hline $500-1000 \mathrm{~m}$ & $\begin{array}{l}2.14(1.85, \\
2.48)\end{array}$ & $\begin{array}{l}1.65(1.44, \\
1.89)\end{array}$ & $\begin{array}{l}1.45(1.21, \\
1.73)\end{array}$ & $1.13(0.98,1.30)$ & $\begin{array}{l}1.06(0.92 \\
1.22)\end{array}$ \\
\hline $1000-2000 \mathrm{~m}$ & $\begin{array}{l}1.92(1.49, \\
2.47)\end{array}$ & $\begin{array}{l}1.63(1.37, \\
1.94)\end{array}$ & $\begin{array}{l}1.23(0.91, \\
1.65)\end{array}$ & $1.03(0.86,1.24)$ & $\begin{array}{l}1.05(0.90 \\
1.21)\end{array}$ \\
\hline$>2000 \mathrm{~m}$ & $\begin{array}{l}0.64(0.09, \\
4.53)^{\mathrm{f}}\end{array}$ & $\begin{array}{l}1.05(0.62, \\
1.80)\end{array}$ & $\begin{array}{l}1.22(0.75, \\
1.99)\end{array}$ & $1.23(0.98,1.55)$ & 1.00 (ref) \\
\hline
\end{tabular}

There was no interaction between these variables $(p=0.49)$.

*: Estimates of relative risks were adjusted for age and its interaction with gender, calendar year of diagnosis, and mental illness in a parent or sibling.

${ }^{\mathrm{f}}$ This estimate was based on one person with schizophrenia, while all other estimates were based on at least 14 people with schizophrenia.

\section{Treatment}

Patients with schizophrenia are generally conscious, and their intelligence is basically normal. Some of them may develop cognitive impairment. The course of the disease is generally prolonged and deteriorated. Diverse treatments are necessary. Medication, such as chlorpromazine and fluoxetine, is the primary choice for the treatment. Many drugs target G-protein-coupled receptors. Plus, researchers attempt to study lipid-based self-nanoemulsifying drug delivery systems formulations to increase the availability of medication. Although medication can control symptoms such as hallucinations, it is difficult to improve cognitive problems. So, psychotherapy is a palliative course of treatment. Hence, the better treatment so far for schizophrenia is a combination of medication and psychological intervention.

\subsection{G-protein-coupled receptors (GPCRs)}

G-protein-coupled receptors are the collective name for a large group of membrane protein receptors responsible for receiving messages in eukaryotes to tell organisms information from their environments. They can bind chemicals and activate a series of intracellular signaling pathways that ultimately cause changes in cells. Moreover, GPCRs play a significant role in the human body because numerous diseases are associated with Gprotein-coupled receptors, and about half of medicines target G-protein-coupled receptors. Therefore, GPCRs also are studied for treating schizophrenia and are promising for medicine discovery.

5-hydroxytryptamine receptors (5-HT receptors), present throughout the nervous system, are profitable targets for drug discovery of treatments for schizophrenia. There are fourteen different 5-HT receptors in the human body, and thirteen are G protein coupled receptors[15]. 5HT receptors and 5-HT are involved in memory, mood, cognition, and many other aspects. A 5-ht2a receptor can block cognitive function [16]. Antipsychotics such as clozapine, olanzapine, quetiapine, etc., can improve cognition for patients with schizophrenia. But these medicines have extrapyramidal side effects (EPS). However, stimulation of 5-HT1A receptors or inhibition of 5-HT3, 5-HT6, and 5-HT2A/2C receptors improves EPS caused by them [17]. In addition, inhibition of 5HT1A, 5-HT3, and 5-HT6 receptors or activation of 5HT4 receptors reduces cognitive deficits [18]. Thus, drugs targeting the 5-HT receptor or 5-HT itself account for a large share of the current and future drug market.

\subsection{Chlorpromazine (CPZ)}

Chlorpromazine belongs to phenothiazine antipsychotics and is easily absorbed orally. Researchers measure the plasma and saliva levels of chlorpromazine hydrochloride. Concentrations of CPZ in saliva are generally 4 to 50 times higher than plasma concentrations. Eventually, the remaining is excreted by the kidney slowly for about 6 to 9 hours. CPZ is used to treat psychiatric and mood disorders by controlling the excitement, feeling less nervousness, decreasing delusions and other symptoms partly due to resisting the dopamine receptors for emotional thinking in the system and restoring the balance of substances in the brain. CPZ also helps patients to consider clearly and take part in daily life with friends and families. However, it has numerous adverse effects, including dry mouth, blurred vision, drowsiness, and so on. It can also cause extrapyramidal reactions when applied in large quantities for a long time, a common adverse reaction of antipsychotic drugs.

Although CPZ is the primary medication, it has poor aqueous solubility. In recent years, researchers have invented Lipid-based self-nanoemulsifying drug delivery systems (SNEDDS) formulations based on chain 
triglycerides to improve the oral bioavailability, solubility, and stability of CPZ. Incomplete dissolution and deposition of drugs in the gastrointestinal (GI) are the main reasons for the low utilization because they are lipophilic. SNEDDS transport poorly water-soluble drugs, such as CPZ, by increasing surface area and reducing droplet size, improving the solubility and absorption of lipophilic drugs. In addition, SNEDDS has been found to increase lipid fluidity of intestinal cell membranes and reduce cytochrome -P450 metabolism in the intestinal tract, thereby improving oral bioavailability.

Table 9. Results of physico-chemical tests on selected formulations by SNEDDS loaded with chlorpromazine. [18]

\begin{tabular}{|c|c|c|c|c|c|c|}
\hline formulation & $\begin{array}{l}\text { Thermodynami } \\
\text { c stability }\end{array}$ & $\begin{array}{l}\text { Drug loading } \\
\qquad(\%)\end{array}$ & $\begin{array}{c}\text { Zeta } \\
\text { potential }\end{array}$ & $\begin{array}{c}\text { Transmittance } \\
(\%)\end{array}$ & $\mathrm{pH}$ & PDI \\
\hline $\begin{array}{l}\text { Small chain triglyceride } \\
\text { (SCT15) }\end{array}$ & stable & 92.3 & -17.1 & 1.5 & $7.3 \pm 1.6$ & $\begin{array}{c}0.27 \pm 0.4 \\
3\end{array}$ \\
\hline $\begin{array}{l}\text { Medium chain triglyceride } \\
\text { (MCT16) }\end{array}$ & stable & 82.7 & -14.2 & 0.1 & $7.3 \pm 1.52$ & $\begin{array}{c}0.33 \pm 0.6 \\
7\end{array}$ \\
\hline $\begin{array}{l}\text { Long chain triglyceride } \\
\text { (LCT14) }\end{array}$ & stable & 85.5 & -21.4 & 0.0 & $7.4 \pm 1.0$ & $\begin{array}{c}0.31 \pm 0.1 \\
7\end{array}$ \\
\hline
\end{tabular}

These distinct characteristics make them superior to conventional trace and non-trace drugs. During the research, people test the solubility of chlorpromazine in all formulation components individually. CPZ is more soluble in ethanol (91\%) than others [18]. Those formulations are prepared and tested as SNEDDS by using 3 types of chain triglycerides: small chain triglyceride, medium chain triglyceride, and long chain triglyceride.
Table 9 indicates that formulations SCT15, MCT6, and LCT14 were the most stable formulations from each group of SNEDDS. They are stored and observed for further research. At last, LCT14 is thought to be the most stable nanoemulsion as it showed no absorbance. Optimizing LCT 14 shows a 1.5 -fold increased elimination half-life $(\mathrm{p}<0.01)$, up to 6 -fold increased oral bioavailability, and 1.7-fold decreased plasma clearance rate $(\mathrm{p}<0.01)$ [18]. Those data demonstrate SNEDDS has tremendous capacity but remains to be explored for facilitating oral lipid delivery. There are only more than 4 types of SNEDDS on the market as of 2019 [19]. Thus, incorporating chlorpromazine into SNEDDS based on LCT14 formulations shall be a promising strategy to enhance its oral bioavailability by increasing solubility, permeability and decreased the first-pass metabolism.

\subsection{Psychological intervention}

Psychological interventions are auxiliary tools for treating schizophrenia. It is the process of influencing patients' psychological problems and personalities step by step under the guidance of psychological theory to change their mental activities toward the doctor's desired goal. There are many categories of psychological interventions involved in schizophrenia.

a) Family intervention

Combined with other evidence-based interventions, family intervention may have a promising way for substantial recovery of function and complete avoidance of psychosis. The meta-analysis concludes that relapse rates are reduced by $50-60 \%$ compared to conventional treatment [20]. Using 4124 individuals tested, researchers find that family interventions also reduce hospitalizations $(\mathrm{r}=0.78)$ and encourage medication adherence $(\mathrm{r}=0.74)$ [21]. It is particularly effective in the early stages of psychiatric disorders because family members are always involved in the process, adjusting their attitudes and interacting with the patient at any time. The improvements are significant and long lasting. Therefore, parents and children must communicate with each other.

b) Cognitive behavioral therapy (CBT)

CBT is a relatively short-term form of psychotherapeutic treatment that helps people to change negative cognition. It focuses on the present thinking and behaviors and identifies and replaces negative ones with more objective and reasonable ideas. The strategy of this therapy is to help the person reconstruct the cognitive structure, re-evaluate himself, rebuild his confidence in himself, and change the perception that he is "bad". There are four specific types of cognitive behavioral therapies with different approaches but the same goal: Cognitive therapy, Dialectical behavior therapy (DBT), Multimodal therapy, and Rational emotive behavior therapy (REBT). The investigators include studies in which adult patients with mental illness between the ages of 18 and 65 who meet DSM-III-R or DSM-IV criteria are randomly assigned to CBT or placebo. There is no significant difference in the rate of loss between CBT and placebo. The combined ratio of complete treatment effectiveness is $4.06(95 \% \mathrm{CI}=2.78-5.92)$. The superiority of CBT over placebo does not rely on the form of a placebo, year of study, or the number of sessions [22].

\section{Conclusion}

Based on the findings discussed above, we can conclude that genetic and environmental influences can risk people 
from getting schizophrenia. These two factors can also interact with each other for further development. As treatment for this disorder, various ways are invented and operated. Thus, the objective for this paper has been met. More research for fields mentioned above in recent years is needed for further analysis on broader and more accurate conclusions for studies in the future.

\section{References}

1. Maric NP, Jovicic MJ, Mihaljevic M, Miljevic C: Improving Current Treatments for Schizophrenia. Drug development research 2016, 77(7):357-367.

2. World Health Organization. (2013, November 7). Gender Differences in the Epidemiology of Affective Disorders and Schizophrenia. World Health Organization.

3. Winklbaur B, Ebner N, Sachs G, Thau K, Fischer G: Substance abuse in patients with schizophrenia. Dialogues in clinical neuroscience 2006, 8(1):37-43.

4. Qing L, Liu L, Zhou L, Zhang F, Gao C, Hu L, Nie $\mathrm{S}$ : Sex-dependent association of mineralocorticoid receptor gene (NR3C2) DNA methylation and schizophrenia. Psychiatry research 2020, 292:113318.

5. Tang L, Zhang Q, Li J, Gu T, Ruan Y, Tang Y, Zhang S, Hu L, Zhao L, Wang G et al: A NR3C2 haplotype increases the risk of alcoholism in schizophrenic patients in Han Chinese population. Psychiatry research 2015, 229(3):1057-1058.

6. Fatjó-Vilas M, Prats C, Pomarol-Clotet E, Lázaro L, Moreno C, González-Ortega I, Lera-Miguel S, Miret S, Muñoz MJ, Ibáñez I et al: Involvement of NRN1 gene in schizophrenia-spectrum and bipolar disorders and its impact on age at onset and cognitive functioning. The world journal of biological psychiatry : the official journal of the World Federation of Societies of Biological Psychiatry 2016, 17(2):129-139.

7. Zhang H, Ju G, Wei J, Hu Y, Liu L, Xu Q, Chen Y, Sun Z, Liu S, Yu Y et al: A combined effect of the KPNA3 and KPNB3 genes on susceptibility to schizophrenia. Neuroscience letters 2006, 402(12):173-175.

8. Wei J, Hemmings GP: The KPNA3 gene may be a susceptibility candidate for schizophrenia. Neuroscience research 2005, 52(4):342-346.

9. Volkow ND: Substance use disorders in schizophrenia--clinical implications of comorbidity. Schizophrenia bulletin 2009, 35(3):469-472.

10. Chan KY, Zhao FF, Meng S, Demaio AR, Reed C, Theodoratou E, Campbell H, Wang W, Rudan I: Urbanization and the prevalence of schizophrenia in China between 1990 and 2010. World psychiatry : official journal of the World Psychiatric Association (WPA) 2015, 14(2):251-252.
11. Veling W, Hoek HW, Wiersma D, Mackenbach JP: Ethnic identity and the risk of schizophrenia in ethnic minorities: a case-control study. Schizophrenia bulletin 2010, 36(6):1149-1156.

12. Veling W, Hoek HW, Mackenbach JP: Perceived discrimination and the risk of schizophrenia in ethnic minorities: a case-control study. Social psychiatry and psychiatric epidemiology 2008, 43(12):953-959.

13. Marcelis M, Takei N, van Os J: Urbanization and risk for schizophrenia: does the effect operate before or around the time of illness onset? Psychological medicine 1999, 29(5):1197-1203.

14. Pedersen CB, Mortensen PB: Urbanization and traffic related exposures as risk factors for schizophrenia. BMC psychiatry 2006, 6:2.

15. McCorvy JD, Roth BL: Structure and function of serotonin G protein-coupled receptors. Pharmacology \& therapeutics 2015, 150:129-142.

16. Meltzer HY, Massey BW: The role of serotonin receptors in the action of atypical antipsychotic drugs. Current opinion in pharmacology 2011, 11(1):59-67.

17. Shimizu S, Mizuguchi Y, Ohno Y: Improving the treatment of schizophrenia: role of 5-HT receptors in modulating cognitive and extrapyramidal motor functions. CNS \& neurological disorders drug targets 2013, 12(6):861-869.

18. Baloch J, Sohail MF, Sarwar HS, Kiani MH, Khan GM, Jahan S, Rafay M, Chaudhry MT, Yasinzai M, Shahnaz G: Self-Nanoemulsifying Drug Delivery System (SNEDDS) for Improved Oral Bioavailability of Chlorpromazine: In Vitro and In Vivo Evaluation. Medicina (Kaunas, Lithuania) 2019, 55(5).

19. Rani S, Rana R, Saraogi GK, Kumar V, Gupta U: Self-Emulsifying Oral Lipid Drug Delivery Systems: Advances and Challenges. AAPS PharmSciTech 2019, 20(3):129.

20. McFarlane WR: Family Interventions for Schizophrenia and the Psychoses: A Review. Family process 2016, 55(3):460-482.

21. Pharoah F, Mari J, Rathbone J, Wong W: Family intervention for schizophrenia. The Cochrane database of systematic reviews 2010(12):Cd000088.

22. Hofmann SG, Smits JA: Cognitive-behavioral therapy for adult anxiety disorders: a meta-analysis of randomized placebo-controlled trials. The Journal of clinical psychiatry 2008, 69(4):621-632. 